\title{
Technical aspects of precision fertilizer application in Northern Great Plain region
}

\author{
Zoltán HAGYMÁSSY \\ University of Debrecen 4032 Debrecen Böszörményi ú. 138.; E-mail: hagymassy@agr.unideb.hu
}

Keywords: fertilizer distributor, transversal unevenness of spreading, unevenness of fertilizer dosage, precision farming

\section{Introduction}

In University of Debrecen, Department of Agricultural Machinery different type's of fertilizer, and fertilizer distributor were examined by authors, within the framework of precision farming. The examinations were conducted in the field conditions. The basis of our study is a research project being carried out at the University of Debrecen, researchers, farmers and contractors involved. The aim of the program is to use precision agriculture, GPS parallel guides and automatic steering system, installation, and calibration of the equipment.

\section{Materials and methods}

The determination of the transverse unevennes of spreading was performed by means of measuring trays. Trays are placed perpendicular to the measuring track. In order to prevent the spillage of the fertilizer particles from the receiving trays, the 500x500 mm receiving trays are equipped with a 50x50 mm split cracking grid. The fertilizer spreader set to the desired parameters passes over the receiving tray row at operating speed. During the measurement, the fertilizer contents of the measuring trays were measured by a digtal scale (accuracy: $0.1 \mathrm{~g}$ ), and the datas were entered to the computer. (Hagymássy \& Ancza 2011). One of the most typical correlation for determining the transversal distribution is the coefficient of variation. (Csizmazia 1993)

$$
\mathbb{E}=\frac{100}{\frac{-}{x}} \sqrt{\frac{\sum_{i=1}^{n}\left(x_{i}-\bar{x}\right)^{2}}{n-1}}
$$

Where:

$\mathrm{xi}$ - the average of the amounts of fertilizers captured at one measuring point during the three measurements, $\mathrm{x}^{-}-$the average of the fertilizer amounts captured at all measuring points during the three measurements, $\mathrm{n}$ - The number of testing trays, $\mathrm{CV}$ - The maximum value is $15 \%$.

\section{Results and discussion}

Measuring trays of standard size and design were placed $100 \mathrm{~m}$ from the edge of the parcel. Dimension of measuring trays: $500 * 500 \mathrm{~mm}$, equipped with anti-cracking grid to prevent the spillage from tray. Working width is: $\mathrm{B}=30.4 \mathrm{~m}$. The spreading width is: $\mathrm{W}$ $=60.8 \mathrm{~m}$, the spreading pattern is triangular. Distribution of the measuring trays: $3.04 \mathrm{~m}$ $\mathrm{x}(11$ trays -1$)=30.4 \mathrm{~m}$ 
First, $100 \mathrm{~m}$ from the edge of the field, fertilizer was distributed. Trays placed within $30.4 \mathrm{~m}$ of working width were fertilizer spreaded forward and backward. The fertilizers collected in the measuring trays were weighed on a digital scale with an accuracy of 0.1 $\mathrm{g}$ and the resulting values were plotted on a chart. It can be stated that the coefficient of variation of transversal way is $\mathrm{CV}=12.28 \%$, less than the standard $\mathrm{CV}>15 \%$ required by the standard, so that the standard deviation is satisfactory. It can also be stated that the mean difference in dosing is also satisfactory e $=9.58 \%$. However, the applied dose rate was much more than the planned amount, so we stopped the fertilizer spreadig, and corrected the adjustment of the dosage mechanism. The test also showed that on the left side of the working width there is a greater amount of particles granules, so correction of the fertilizer spreader is also required.

As a second step, the measuring trays were placed in the middle of the field. It can be stated that the coefficient of variation of the transverse spreading is $\mathrm{CV}=15.92 \%$, which is above the standard value. After corrected the adjustment parameters, the uniformity of the standard deviation would be satisfactory. The amount of dosing was very accurate at $498 \mathrm{~kg} / \mathrm{ha}$. We have found that the transversal evennes of soreading have improved, and the dosage has become more accurate.

\section{Conclusions}

The examinations are preceded by control measurements of the fertilizer granules which basically affected the machine settings. The unevenness of fertilizer dosage quantity is an important aspect due to the application analyzes, while the transversal unevenness of spreading is an important aspect due to the even fertilizer distribution. Based on our measurements we concluded that the fertilizer spreaders dosage quantity and the transversal unevenness of spreading significantly influence the work quality.

\section{Acknowledgement}

The research was financed by the Higher Education Institutional Excellence Programme of the Ministry of Human Capacities in Hungary, within the framework of the 4.thematic programme of the University of Debrecen, and the projects "GINOP-2.2.1-15-2016-00001

- Developing a scale-independent complex precision consultancy system" and "EFOP3.6.3-VEKOP-16-2017-00008".

\section{References}

Hagymássy Z., Ancza E., (2011): Experience of an Intensive Program Course on Utilization of High Technology Equipment, Agrárinformatika 2011, Agricultural Informatics Debrecen, Hungary. 2011. p. 80-86.

Csizmazia Z. (1993): Technical Conditions Of Equalized Fertilizer Applications. Hungarian Agricultural Research, 1993/12. p. 16-22. 